Karakuş Aktan, E. N., Aslan, C. ve Yalçın, A. (2021). Okuma stratejisi eğitiminin matematik dersi problem çözme becerisine etkisi. Ana Dili Ĕgitimi Dergisi, 9(2), 381-394.

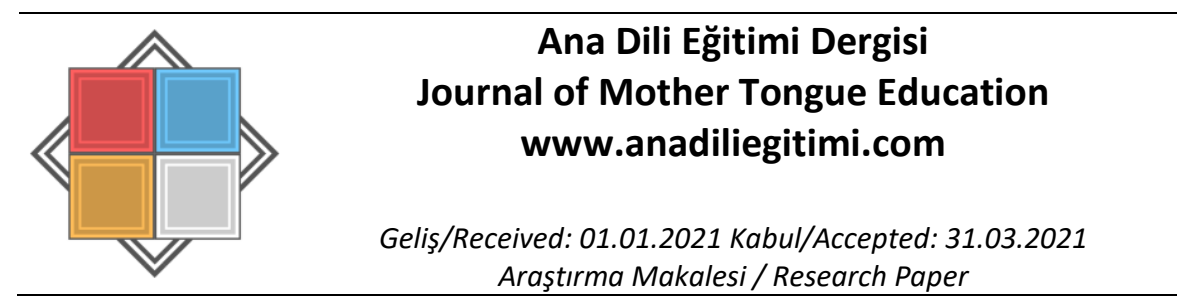

\title{
Okuma Stratejisi Eğitiminin Matematik Dersi Problem Çözme Becerisine Etkisi*
}

\author{
Eda Nur KARAKUŞ AKTAN** \\ Canan ASLAN ${ }^{* * *}$ \\ Alemdar YALÇIN $N^{* * *}$
}

\begin{abstract}
Öz
Okuduğunu anlama becerisi, ana dili öğretiminde dört temel dil becerisinden biri olmakla birlikte yalnızca ana dilinin gelişmesinde değil diğer derslerin başarısında da oldukça önemlidir. Amacı, okuma stratejisi eğitiminin matematik dersi problem çözme becerisine etkisini belirlemek olan bu araştırmada, ön - son test kontrol gruplu yarı deneysel desen kullanılmıştır. Araştırma, ilgili yerlerden gerekli izinler alınarak 2017-2018 eğitim öğretim yılında, Ankara ilindeki bir devlet ortaokulunun iki 6. sınıf şubesiyle gerçekleştirilmiştir. Sınıf mevcudu, matematik ve Türkçe dersi akademik başarıları birbirine denk olan, Türkçe ve matematik derslerini aynı öğretmenlerin yürüttüğü iki 6. sınıf seçilmiş; yansız atama yoluyla sözü edilen sınıflardan biri kontrol, biri deney grubu olarak belirlenmiştir. Araştırmada, deney grubuna okuma stratejilerine göre hazırlanmış etkinlikler uygulanırken kontrol grubundaki dersler, ders kitabındaki etkinliklerle yürütülmüştür. Uygulama çalışması on haftada tamamlanmıştır. Araştırma sonucunda, okuma stratejisi eğitimi verilen deney grubu öğrencilerinin matematik dersi problem çözme başarı testi puanlarının kontrol grubu öğrencilerinin puanlarından daha yüksek olduğu belirlenmiştir. Deney grubu öğrencilerinin on haftalık uygulama sonrası matematik problem çözme becerilerinin geliştiği sonucuna ulaşılmıştır.
\end{abstract}

Anahtar Kelimeler: Okuma becerisi, okuma stratejileri, matematik problem çözme becerisi

\section{The Effect of Reading Strategy Education on Problem Solving Skills in Mathematics Abstract}

Reading comprehension skill is one of the four basic language skills in native language teaching, but it is very important not only for the development of native language but also for the success in other lessons. In this study, the purpose of which was to determine the effect of reading strategy education on problem solving skills in mathematics lessons, a quasi-experimental design with pretest - posttest control groups were used. By getting the necessary permissions from the relevant places, the research was carried out with two 6th grade classes of a secondary school in Ankara in the 2017-2018 academic year. Two 6th grade classes whose class sizes and math and Turkish courses' academic achievements were equal and Turkish and mathematics lessons were taught by the same teachers were chosen; one of these classes was determined as the control group and the other as the experimental group through random method. In the study, while

\footnotetext{
* Bu çalışma, Prof. Dr. Canan ASLAN danışmanlığında, Prof. Dr. Alemdar YALÇıN’ın eş danışmanlığında yazılan "Okuma Stratejisi Eğitiminin Ortaokul Öğrencilerinin Okuduğunu Anlama ve Matematik Dersindeki Problem Çözme Becerilerine Etkisi" adlı doktora tezinin verilerinden yararlanılarak hazırlanmıştır.

${ }^{* *}$ Arş. Gör. Dr., Gazi Üniversitesi, Gazi Eğitim Fakültesi, Türkçe ve Sosyal Bilimler Eğitimi, Ankara, edanurkaraks@gmail.com, ORCID: 0000-0001-7010-1104

*** Prof. Dr., Ankara Üniversitesi, Eğitim Bilimleri Fakültesi, Türkçe ve Sosyal Bilimler Eğitimi, Ankara, caslan@ankara.edu.tr, ORCID: 0000-0002-0015-286X

**** Prof. Dr., Gazi Üniversitesi, Gazi Eğitim Fakültesi, Türkçe ve Sosyal Bilimler Eğitimi Bölümü, Ankara, alemdaryalcin@gmail.com, ORCID: 0000-0001-5618-277X
} 
activities prepared according to reading strategies were applied to the experimental group, the lessons in the control group were carried out with the activities in the textbook. The application study was completed in ten weeks. As a result of the research, it was determined that mathematical problem solving achievement test scores of the experimental group students, who were provided reading strategy education, were higher than the MPSAT scores of the students in the control group. It was concluded that after ten weeks of application, mathematical problem solving skills of students in the experimental group have developed.

Keywords: Reading skill, reading strategies, mathematical problem solving skills

\section{Giriş}

Ana dili öğretimi dört temel dil becerisinin geliştirilmesiyle gerçekleştirilir. Bireyin ana dilini etkili ve doğru bir biçimde kullanabilmesi dört dil becerisinin geliştirilmesiyle doğru orantılıdır. Her beceri tek tek çok önemli ve birbirini tamamlayıcı niteliktedir; bu nedenle birinin diğerinden daha önemli ya da önemsiz olması söz konusu değildir fakat her beceri alanın geliştirilmesinde farklı uygulamalar yürütülmesi gerekmektedir. Dört dil becerisinden biri olan okuma becerisini de bireyler formal eğitim sürecinde edinirler ve geliştirirler. Okuma, yazılı olan sembolleri seslendirme ve bu seslendirmenin verdiği iletiyi anlama (Bloomfield, 1942, s. 129), okuyucu ile yazarın aktif ve etkili iletişimine gereksinim duyulan dinamik bir anlam kurma sürecidir (Akyol, 2012, s. 33). Okumanın öncelikle fiziksel boyutunun gerçeklemesi gerekmektedir. Okuma tabii ki sadece fiziksel unsurlardan oluşan bir süreç değildir. Okumanın gerçekleşebilmesi kavramanın, anlam kurmanın başka bir ifadeyle zihinsel sürecin etkin duruma gelmesiyle mümkündür. Buradan hareketle okumanın fiziksel ve zihinsel boyutları kapsayan karmaşık bir süreç olduğu ifade edilebilir. Anlamanın gerçekleşmediği bir okuma sürecinde yalnızca fiziksel boyut tamamlanmış olur ve okumanın zihinsel boyutu eksik kalır. Bu nedenle "anlama" kavramı oldukça önemlidir ve okumanın zihinsel boyutunu vurgulamaktadır.

Okul döneminde edinilen ve geliştirilen okuma becerisi, yalnızca ana dili öğretiminde değil öğrencilerin diğer derslerinde hatta tüm yaşamları boyunca kullanacakları bir eylem olarak hayatlarında oldukça büyük bir öneme sahiptir. Sever (2011, s. 11), Türkçe dersinde kazandırılması gereken bilgi ve becerilerin bireyin tüm yaşamında gerekli olan bilgi ve becerilerle örtüştüğünü belirterek Türkçeyi kullanma becerisini bütün derslerin temeline almaktadır. Bütün dersler için iletişim aracının dil olması nedeniyle dilsel becerileri gelişmeyen öğrenciler, diğer derslerde de başarısız olmaktadır (Aslan, 2017, s. 728).

Bireyler, hem okul ortamında hem de okul dışı ortamlarda kendilerine gerekli olan bilgileri okuma yoluyla edinmekle birlikte iş yaşamlarında da bilgi alışverişlerini çoğunlukla okuma yoluyla yaparlar. Buradan hareketle okuma eğitimini bir ağaca benzetmek mümkündür; sözü edilen ağacın serpilmesi ve sürekli gelişmesi için köklerinin sağlam bir şekilde yapılandırılması gereklidir (Yalçın, 2018, s. 54). Bireyin yaşamında bu denli önemli bir etken olan okuduğunu anlama becerisinin geliştirilmesi için farklı çalışmalar yapılmalı ve öğrencilere okuduğunu anlama sürecini destekleyen stratejiler öğretilmelidir.

Dil öğretiminde strateji kavramı, bir işe yönelik planlanmış yaklaşımlar olarak ifade edilebilir. Okuma stratejileri de okuduğunu anlamayı gerçekleştirmek amacıyla geliştirilmiştir. Okuduğunu anlama stratejileri, anlamı yapılandırma süreçlerini kolaylaştıran ve bu süreçte karşılaşılan problemlerin çözümünde katkı sağlayan ve bilinçli bir şekilde gerçekleştirilen eylemlerdir (Baştuğ, Hiğde, Çam, Örs ve Efe, 2019, s. 31).

Okuduğunu anlama stratejileri, bireylerin okuma sırasında anlamayı nasıl gerçekleştirdikleri ya da anlama gerçekleşmediğinde ne yapmaları gerektiği konusunda yol gösterici niteliktedir. Bu stratejiler, okuduğunu anlamayı geliştirmek ve kavrama konusundaki yetersizliklerle baş etme noktasında bilişsel becerileri artırmak amacıyla kullanılır (Karatay, 2014, s. 41-42). Okuduğunu anlama stratejilerinde, sürece dayalı isimlendirilme yapılmış olmakla birlikte alanyazında okuma sürecinin her aşamasında kullanılan stratejilerin de sayısı oldukça fazladır.

Okuma öncesi, sırası ve sonrası stratejilerin yanında okuma sürecinin tamamında kullanılan stratejilerin sayısı oldukça fazla olduğu için hepsini burada verebilmek mümkün değildir. Bu stratejilerden bazıları: SQ3R, K-W-L, Çoklu geçiş stratejisi, SCAN and RUN, Not Alma'dır. Bu stratejilerin 
ortak amaçları, metnin daha iyi, doğru ve kalıcı bir biçimde anlaşıımasını sağlayarak öğrencilerin metinlere farklı açılardan bakabilmelerini; yaratıcı ve eleştirel düşünme gibi üst düzeyde yer alan düşünme becerilerini de geliştirmelerini sağlamaktır. Belirtilen ortak amaç çerçevesinde her bir stratejinin özel amaçları ve kullanım şekilleri farklıdır.

Bloom'a (1998, s. 49) göre, bireyin tüm yaşamı boyunca okul öğrenmelerinde ilkokul yıllarında kazanılan okuduğunu anlama becerisinin etkisi çok büyüktür. Okuduğunu anlama kelimeleri akılda şemalarla ilişkilendirerek ilgili yeni bir durum yaratma süreci olarak kabul edilebilir. Bu süreçte; bir metin veya problem üzerine düşünme, problemin nedenlerini arama, sonuç elde etme, yorumlama, analiz etme, sentezleme ve değerlendirme gibi zihinle ilgili etkinlikler etkilidir (Güneş, 2013). Bu denli önemli zihinsel etkinlikleri kapsayan bir eylem olan okuduğunu anlama becerisinde istenilen seviyeye ulaşılamamıştır. Okuduğunu anlama becerisinde istenilen seviyelere ulaşılamadığının göstergelerinden biri de ABIDE 2016 (Akademik Becerilerin İzlenmesi ve Değerlendirilmesi) sınav sonuçlarıdır. PISA ve PIRLS gibi uluslararası sınavların benzeri olarak nitelendirilebilecek ABIDE 2106 Projesinin amacı, Türkiye genelindeki 8. sınıf öğrencilerinin katılımıyla öğrenci başarısına yönelik ilerlemelerin izlenmesidir. Bu amaç çerçevesinde öğrencilerin; Türkçe, Matematik, Fen Bilimleri ve Sosyal Bilgiler alanlarında akademik ilerlemeleri beş yeterlik düzeyi belirlenerek incelenmiştir. Bu araştırmada, öğrencilerin Türkçe okuduğunu anlama düzeylerinin istenen seviyede olmadığı sonucuna ulaşılmıştır. Ana dili dersleri dışındaki derslerin öğretim materyallerinin büyük bir kısmı da okumaya dayalıdır. Bu nedenle okuma becerisine tüm derslerde ihtiyaç duyulmaktadır. PISA, PIRLS gibi uluslararası düzeyde yapılan sınav sonuçlarına göre okuduğunu anlama becerisinin geliştirilmesi gerektiği ortaya çıkmaktadır. Öğrencilerimizin bu uluslararası sınavlarda düşük seviyelerde oldukları görülmektedir. Bu sınavlar okuma, fen ve matematik bilimleri olarak sınıflandırılmıs olmakla birlikte fen bilimleri ve matematik becerilerini ölçen soruların da okuduğunu anlama becerisine dayalı olduğu görülmektedir. Bireylerin bilgileri ezberlediği ve olduğu gibi aktardığı bir süreç değil; öğrendiklerini yaşamlarına aktarabildikleri, yeni durumlara uyarlayabildikleri ve problem çözme becerilerini geliştirebildikleri bir eğitim-öğretim süreci gelişen ve değişen dünyaya uyumun sağlanabilmesi açısından oldukça önemlidir.

Problem kavramı TDK (2020) tarafından "teoremler ya da kurallar yardımıyla çözülmesi istenen soru veya mesele" olarak tanımlamaktadır. Problem çözme de bu soru ve meseleler için çözüm yolu ya da yolları üretme olarak tanımlanabilir. Çok boyutlu ve karmaşık bir süreci içinde barındıran problem çözme; problemi anlama, verilerin içinden çözüm için ihtiyaç olan bilgiyi seçme, seçilen bilgilerin matematiksel imgelere dönüştürülmesi ve gerekli işlem basamaklarının takibiyle çözüme ulaşma ögelerinden oluşmaktadır. Doğrusal bir yol izlememekle birlikte bu ögelerin en önemli ve ilk aşamasının okuduğunu anlama olduğu ve okuduğunu anlama başarılı bir şekilde gerçekleşmediğinde problemde verilen sayıları rastgele kullanarak bireylerin anlamsız sonuçlara ulaşacakları belirtilmektedir (Goos, Galbraith ve Renshaw, 2000; Olkun ve Toluk, 2004). Bu düşüncelerden hareketle yapılan çalışmalarda da alanyazını destekleyen sonuçlara ulaşımıştır (Yurttaş Kumlu, 2016; Ulu, 2011; Tuohimaa, Aunola ve Nurmi, 2008; Grimm, 2008; Jordan, Hanich \& Kaplan, 2003).

Matematik dersi problem çözmenin ilk aşaması, problemin okunarak anlaşılmasıdır. Ancak problem okunup anlaşıldıktan sonra sonuca ulaşmak için gerekli işlemlerin yapılması mümkündür. Problemler genellikle metin temellidir. Bu metinden yola çıkılarak üretilen matematiksel işlemler cevaplanması gereken durumu/soruyu çözüme ulaştııı. Bu nedenle okuduğunu anlamada sorun yaşayan öğrencilerin problem çözmede de zorlanacağı düşünülebilir.

Okuduğunu anlama becerisinin nasıl geliştirileceği, bu becerinin geliştirilmesinde izlenecek strateji, yöntem ve teknikler konusunda alanyazında birçok yayın bulunmaktadır ancak okuduğunu anlamanın diğer disiplinlerle olan ilişkisi üzerine yapılan çalışmalar sınırlı sayıdadır ve bu çalışmaların çoğu genel olarak tarama modelinde yürütülmüştür (Ajello, Caponeram ve Palmerio, 2018; Özcan Tepe, 2016; Tüzer, 2016; Yurttaş Kumlu, 2016; Özsoy, Kuruyer ve Çakıroğlu, 2015; İlhan, 2014; Kıvrak, 2014; Özdemir, 2013; Ulu, 2011; Hite, 2009; Grimm, 2008; Walker, Zhang ve Surber, 2008). Türkçe dersinin bir beceri dersi olmasından ve bu derste geliştirilen becerilerin diğer derslerde hatta tüm yaşam boyunca bireye gerekli olduğundan ana dili öğretimi sürecinin iyi bir şekilde planlanması ve bu becerilerini etkili biçimde kullanmalarını sağlamak amacıyla öğrencilere beceri eğitiminin verilmesi gerekmektedir. Buradan hareketle okuma stratejisi eğitimi verilen öğrencilerin matematik dersi 
problem çözme becerilerinde gelişme gösterecekleri düşünülmektedir. Bu nedenle çalışmada, okuma stratejilerinin ortaokul 6. sınıf öğrencilerinin matematik dersi problem çözme becerilerine etkisi üzerinde durulmuş ve "Okuma stratejileri eğitiminin verildiği 6 . sınıf öğrencilerinin matematik dersi problem çözme becerileri ile bu eğitimin verilmediği öğrencilerin matematik dersi problem çözme becerileri arasında istatistiksel olarak anlamlı bir farklılık var mıdır?" sorusuna yanıt aranmıştır.

Araştırmanın amacı, 6. sınıf öğrencilerine yönelik okuma stratejisi eğitiminin ortaokul matematik dersi problem çözme becerilerine etkisini belirlemektir. Bu amaca yönelik alt amaçlar şu şekilde sıralanmıştır:

1.Kontrol grubu öğrencilerinin Matematik Problem Çözme Başarı Testi (MPÇBT) ön - son test puanları arasındaki fark anlamlı mıdır?

2.Deney grubu öğrencilerinin MPÇBT ön - son test puanları arasındaki fark anlamlı mıdır?

3.Okuma stratejilerine yönelik hazırlanan etkinliklerin uygulandığı deney grubu ile mevcut Türkçe Öğretimi Programına yönelik hazırlanan etkinliklerin uygulandığı kontrol grubu öğrencilerinin MPÇBT puanları, eğitim sonrasında deney grubunun lehine anlamlı bir farklıık göstermekte midir?

\section{Araştırmanın Modeli}

\section{Yöntem}

Araştırmada, okuma stratejileri eğitiminin 6. sınıf öğrencilerinin matematik problemlerini çözme becerilerine etkisini belirleyebilmek için planlanmış etkinlikler içeren ön test-son test kontrol gruplu yarı deneysel desen kullanılmıştır. Deneysel desen ise, araştırmacının kontrolünde yürütülen ve değişkenler arası neden-sonuç ilişkilerini ortaya çıkarmak amacıyla çözümleme yapılması istenen verilerin oluşturulduğu araştırma türüdür (Büyüköztürk, 2000; Karasar, 2005). Eğitim alanında yapılan araştırmalarda çok tercih edilen yarı deneysel desen de tüm değişkenlerin kontrol edilmesinin olanaksız olduğu durumlarda kullanılan bir deneysel desendir (Büyüköztürk, 2014). Yapılan etkinliklerin etkili olup olmadığını belirlemek amacıyla kullanılan model Tablo 1'de verilmiştir:

Tablo 1.

Araştırmanın Yöntem Modeli

\begin{tabular}{clll}
\hline \multicolumn{1}{c}{ Yarı Deneysel Desen } \\
\hline Gruplar & \multicolumn{1}{c}{ Ön Test } & \multicolumn{1}{c}{ Uygulama } & \multicolumn{1}{c}{ Son Test } \\
\hline \multirow{3}{*}{ Deney Grubu } & Matematik Problem & Okuma stratejileri & Matematik Problem \\
& Çözme Başarı Testi & $\begin{array}{l}\text { kullanılarak hazırlanan } \\
\text { etkinliklerin } \\
\text { (MPÇBT) }\end{array}$ & $\begin{array}{l}\text { Çözme Başarı Testi } \\
\text { (MPÇBT) }\end{array}$ \\
& & Mygulanması & \\
\hline \multirow{3}{*}{ Kontrol Grubu } & Matematik Problem & MEB ders kitabındaki & Matematik Problem \\
& Çözme Başarı Testi & etkinliklerin & Çözme Başarı Testi \\
& (MPÇBT) & uygulanması & (MPÇBT)
\end{tabular}

Deney ve kontrol grubu öğrencilerinin matematik dersi problem çözme becerileri uygulama öncesinde (ön test) ve uygulama sonrasında (son test) ölçülmüş ve böylece okuduğunu anlamaya yönelik hazırlanan etkinliklerin deney grubunda bir etkisinin olup olmadığı belirlenmiştir.

\section{Örneklem / Araştırma grubu}

Araştırma, Ankara ilinde bulunan ortaokullardan basit seçkisiz yöntemle belirlenen MEB'e bağlı bir devlet okulunda 2017-2018 eğitim öğretim yılında 6. sınıf düzeyinde iki farklı şubede öğrenim gören 80 öğrenci ile gerçekleştirilmiştir. Okuldaki dört farkı 6. sınıf şubesine "Matematik Problem Çözme Başarı Testi" uygulanmış, uygulama sonunda başarı testinden aldıkları puanlar aynı olan iki 6. sınıf şubesi matematik ve Türkçe dersi karne notlarına da bakılarak seçilmiştir. Seçilen iki şubenin biri seçkisiz yolla deney grubu, diğeri kontrol grubu olarak atanmıştır. Her iki grubun Türkçe ve matematik dersi öğretmenleri aynıdır. 
Araştırmanın yapılacağı okul belirlendikten sonra okul yöneticileri ve ilgili öğretmenlerle görüşülmüş, onlara araştırmaya gönüllü olarak katkı sağlayıp sağlayamayacakları sorulmuştur. Olumlu dönüt sonucunda Ankara ilı Millî Eğitim Müdürlüğünden gerekli resmî izinler alınmıştır.

Tablo 2.

Araştırmaya Katılan Öğrencilerin Cinsiyete Göre Dağılımları

\begin{tabular}{lcc}
\hline Cinsiyet & Deney Grubu & Kontrol Grubu \\
\hline Kız & 20 & 16 \\
\hline Erkek & 17 & 20 \\
\hline Toplam & 37 & 36 \\
\hline
\end{tabular}

Çalışmaya katılan deney ve kontrol grubundaki öğrencilerin sayıları her iki grup için 40 olsa da öğrencilerden bazılarının farklı nedenlerden ön test ve son teste katılamamaları sebebiyle araştırmada deney grubunda 37 öğrenci, kontrol grubunda 36 öğrenci olmak üzere toplam 73 öğrencinin verileri kullanılmıştır.

\section{Veri Toplama Araçları}

Araştırmada, matematik eğitimi uzman görüşleri alınarak dört farklı yayın evinin matematik dersi soru bankalarından sorular taranmış ve araştırmacı tarafından "Matematik Problem Çözme Başarı Testi" (MPÇBT) geliştirilmiştir. Verilerin toplanmasında Matematik Problem Çözme Başarı Testi'nden yararlanılıış̧ır.

\section{İşlem / Verilerin Toplanması}

Deney ve kontrol gruplarında on hafta boyunca eş zamanlı olarak aynı metinler aynı öğretmen tarafından işlenmiştir. Kontrol grubunda metinler yalnızca ders kitabı ve çalışma kitabındaki etkinliklerle işlenirken; deney grubunda araştırmacı tarafından okuma stratejileri eğitimine göre planlanan etkinlikler ve uygulamalarla ders işleme süreci yürütülmüştür. Diğer bir ifadeyle deney ve kontrol grubunda on hafta boyunca aynı metinler farklı etkinliklerle ve uygulamalarla işlenmiştir.

\section{Verilerin Analizi}

Verilerin analizinde, SPSS 25 istatistik paket programı kullanılmıştır. Değişkenlerin belirlenmesinde ortalama, standart sapma ile yüzde ve sıklık değerleri kullanılmıştır. Bağımlı iki grup arasındaki farklılıklar, parametrik testin ön şartları sağlandığında "Eşleştirme t Testi"; sağlamadığında da "Wilcoxont Testi" ile değerlendirilmiştir. Kategorik değişkenler arasındaki ilişkiler "Fisher's Exact Test" ve "Ki Kare" testi ile analiz edilmiştir. Beklenen sıklıkların \%20'den küçük olması durumunda, bunların çözümlemeye dâhil edilmesi için "Monte Carlo Simulasyon Yöntemi" ile değerlendirme yapılmıştır. İstatistik olarak " $\mathrm{p}<0,05$ " sonucunun anlamlı olduğu kabul edilmiştir.

\section{Geçerlik ve Güvenirlik}

Bu çalışmada, "Matematik Problem Çözme Başarı Testi" için matematik öğretmenlerinden görüş alınmış ve en çok tercih edilen yayınevlerinin matematik test kitapları belirlenmiş ayrıca büyük kitabevleriyle görüşülerek en çok satılan matematik test kitaplarının listesi alınmıştır. Öğretmenlerden ve kitabevlerinden alınan bu listelerde en çok tekrarlanan dört yayınevinin test kitapları matematik problem çözme başarı testini hazırlamak için tercih edilmiştir. Belirlenen dört yayın: İzmirli ve İzmirli (2016); Karakök (2015); Tudem (2015); Yılmaz Ay ve Atış (2015) yayınlarıdır. Tercih edilen bu test kitaplarının araştırmanın konusuyla ilgili soruları incelenmiş ve 65 soruluk madde havuzu oluşturulmuştur. Bir matematik eğitimi uzmanıyla çalışılarak 65 soruluk madde havuzundan eleme yapılarak 15 sorudan oluşan bir matematik problem çözme başarı testi geliştirilmiş̧ir. Geliştirilen bu başarı testi, beş Türkçe eğitimi uzmanı ve beş matematik eğitimi uzmanından düzeye ve okuduğunu anlamaya uygunluk bakımından "Uzman Görüşü Formu" yla görüş alınarak düzenlenmiştir. Pilot çalışma 
için MPÇBT, testte yer alan soru sayısının beş katı kadar öğrenciye (75 öğrenci) uygulanmıştır. Uygulama sonucunda geçerlik güvenirlik testi yapılmış; sonuçları Tablo 3'te sunulmuştur:

Tablo 3.

Matematik Problem Çözme Başarı Testi Güvenirlik Testi

\begin{tabular}{lcccc}
\hline & $\begin{array}{c}\text { Ölçekten Madde } \\
\text { Silindig̈inde } \\
\text { Geçerli Olacak } \\
\text { Ortalama }\end{array}$ & $\begin{array}{c}\text { Ölçekten Madde } \\
\text { Silindiğinde Geçerli } \\
\text { Olacak Varyans }\end{array}$ & $\begin{array}{c}\text { Madde Toplam } \\
\text { Korelasyonları }\end{array}$ & $\begin{array}{c}\text { Ölçekten Madde } \\
\text { Silindikten Sonra } \\
\text { Güvenirlik Katsayısı }\end{array}$ \\
\hline 1.Soru & 3,5068 & 6,392 &, 368 &, 738 \\
\hline 2.Soru & 3,5479 & 5,890 &, 583 &, 712 \\
\hline 3.Soru & 3,7808 & 5,729 &, 594 &, 709 \\
\hline 4.Soru & 3,9726 & 6,860 &, 148 &, 762 \\
\hline 5.Soru & 4,1781 & 7,398 &,- 038 &, 765 \\
\hline 6.Soru & 4,2466 & 7,411 &, 000 &, 756 \\
\hline 7.Soru & 4,1781 & 7,065 &, 208 &, 750 \\
\hline 8.Soru & 3,7260 & 5,868 &, 529 &, 718 \\
\hline 9.Soru & 4,0137 & 6,541 &, 316 &, 731 \\
\hline 10.Soru & 4,0959 & 6,477 &, 439 &, 741 \\
\hline 11.Soru & 4,1507 & 6,796 &, 340 &, 722 \\
\hline 12.Soru & 3,9589 & 6,068 &, 505 &, 750 \\
\hline 13.Soru & 4,1644 & 7,028 &, 209 &, 710 \\
\hline 14.Soru & 3,7123 & 5,736 &, 591 &, 112 \\
\hline 15.Soru & 4,2192 & 7,285 & & \\
\hline
\end{tabular}

Güvenirlik çalışması sonucunda, testte 0,20 değerinden düşük iki soru (5. ve 6. sorular) bulunmuş ve bu testin güvenirlik katsayısına bakılmıştır. Güvenirlik için 0 ile +1 arasında değişen değerler kabul edilse de +1 'e yakın değerler alınması istenir. Güvenirlik katsayısının 0,70'ten fazla olması araştırmalarda istenilen bir sonuçtur. Ölçme aracının her bir maddesi kesikli bir şekilde ölçeklendiğinden güvenirliğe cronbachalfa $(\alpha)$ güvenirliği, iç tutarlılık olarak bir güvenilirlik anlamı vardır (Cronbach, 1951). Araştırmada uygulanan testin cronbachalfa $(\alpha)$ katsayısı Tablo 4'te gösterilmiştir.

Tablo 4

Matematik Problem Çözme Başarı Testi Güvenirlik Katsayısı

\begin{tabular}{lcc}
\hline & Madde Sayısı & Güvenirlik Katsayısı \\
\hline Pilot Uygulamada Kullanılan Test & 15 & 0,752 \\
\hline
\end{tabular}

Pilot uygulama çerçevesinde kullanılan 15 madde için cronbachalfa $(\alpha)$ güvenirlik katsayısı 0,752 olarak hesaplanmıştır. Sözü edilen katsayının 0,70 'in üzerinde olması nedeniyle testin uygun şekilde olduğu sonucuna ulaşılmıştır (Cronbach, 2004). Fakat pilot uygulamada öğrencilerin soruları süre olarak yetiştirmekte zorlandıkları belirlenmiş ve matematik öğretmenlerinden de alınan görüşler doğrultusunda "Matematik Problem Çözme Başarı Testi"nde on sorunun olmasının daha uygun olacağı düşüncesiyle diğer sorulara göre daha düşük güvenirlik katsayısına sahip olan beş soru başarı testinden çıkarılmış ve test, uygulama için hazır duruma getirilmiştir.

\section{Araştırma ve Yayın Etiği}

Bu çalışmada "Yükseköğretim Kurumları Bilimsel Araştırma ve Yayın Etiği Yönergesi" kapsamında uyulması belirtilen tüm kurallara uyulmuştur. Yönergenin ikinci bölümü olan "Bilimsel Araştırma ve Yayın Etiğine Aykırı Eylemler" başlığı altında belirtilen eylemlerden hiçbiri gerçekleştirilmemiştir. 


\section{Etik Kurul izni}

Araştırma Millî Eğitim Bakanlığına bağlı bir ortaokulda gerçekleştirildiği için Millî Eğitim Bakanlı̆̆ından gerekli izinler alınmıştır. Ankara Üniversitesi Sosyal Bilimler Alt Etik Kurulu, Millı̂ Eğitim Bakanlı̆̆ından alınan izinlerin yeterli olması ve insan üzerinde yapılan bir çalışma olmaması gerekçesiyle etik kurul onayına ihtiyaç duyulmadığı kararı almıştır.

Kurul adı = Ankara Üniversitesi Sosyal Bilimler Alt Etik Kurulu

Karar tarihi $=22 / 04 / 2019$

Belge sayı numarası $=182$

\section{Bulgular}

Çalışmanın bu bölümünde araştırmanın problem cümlesinden hareketle belirlenmiş olan alt problemlere ilişkin bulgular yer almaktadır. "Kontrol grubu öğrencilerinin MPÇBT ön - son test puanları arasında anlamlı bir farklılık bulunmakta mıdır?" şeklinde ifade edilen birinci alt probleme yönelik bulgular Tablo 5'te sunulmuştur:

Tablo 5.

Kontrol Grubuna Ait MPÇBT ve Ön Test Puanları ile Son Test Puanlarına Iliş̧kin Sonuçlar

\begin{tabular}{llcccccc}
\hline Grup & $\mathrm{N}$ & Ortalama & Std. Sapma & Std. Hata & $\mathrm{t}$ & $\mathrm{p}$ \\
\hline \multirow{2}{*}{ Kontrol } & MPÇBT Ön Test & 36 & 4,06 & 2,14 & 0,36 & 0,21 & 0,84 \\
\cline { 2 - 9 } & MPÇBT Son Test & 36 & 4,03 & 2,09 & 0,35 & & \\
\hline
\end{tabular}

$* * p<0,01$

Tablo 5'te kontrol grubunda, MPÇBT uygulama öncesi puanlar ve uygulama sonrası puanlar arasında istatistiksel olarak anlamlı bir farklılık olmadığı görülmektedir $(p=0,84)$. Elde edilen bu bulgulara göre, mevcut ders kitabına göre yürütülen Türkçe dersinin öğrencilerin matematik dersi problem çözme becerilerine olumlu yönde bir katkısının olmadığını söylemek mümkündür.

İkinci alt problem olan "Deney grubu öğrencilerinin MPÇBT ön - son test puanları arasında anlamlı bir farklılık var mıdır?" sorusuna yönelik bulgular Tablo 6' da verilmiştir:

Tablo 6.

Deney Grubuna Ait MPÇBT Ön Test Puanları ile Son Test Puanlarına Iliş̧kin Sonuçlar

\begin{tabular}{lllccccc}
\hline \multirow{2}{*}{ Geney } & N & Ortalama & Std. Sapma & Std. Hata & t & $\mathrm{p}$ \\
\hline & MPÇBT Ön Test & 37 & 2,81 & 1,60 & 0,26 & $-13,89$ & $0,00^{* *}$ \\
\cline { 2 - 8 } & MPÇBT Son Test & 37 & 5,46 & 2,01 & 0,33 & & \\
\hline
\end{tabular}

$* * p<0,01$

Tablo 6'ya göre deney grubunda, MPÇBT uygulama öncesi ve sonrası puanları arasında istatistiksel olarak anlamlı fark olduğu belirlenmiştir $(p<0,01)$. Bu bulgulardan hareketle, okuma stratejilerinin geliştirilmesine yönelik hazırlanmış olan uygulamaların öğrencilerin matematik dersi problem çözme becerilerinin gelişmesinde olumlu yönde katkı sağladığı söylenebilir.

Araştırmanın üçüncü alt probleminde "Okuma stratejilerine yönelik hazırlanan etkinliklerin uygulandığı deney grubu ile mevcut Türkçe Dersi Öğretim Programı'na yönelik hazırlanan etkinliklerin uygulandığı kontrol grubu öğrencilerinin MPÇBT puanları, eğitim sonrasında deney grubunun lehine anlamlı bir farklılık göstermekte midir?" sorusuna cevap aranmış ve buna ilişkin bulgular Tablo 7'de sunulmuştur:

Tablo 7.

Deney - Kontrol Gruplarının MPÇBT Ön - Son Test Puanlarının Karşılaştırılması 


\begin{tabular}{cccccccc}
\hline \multirow{2}{*}{ Grup } & & $\mathrm{N}$ & Ortalama & $\begin{array}{c}\text { Std. } \\
\text { Sapma }\end{array}$ & Std. Hata & $\mathrm{t}$ & $\mathrm{p}$ \\
\hline \multirow{2}{*}{ MPÇBT Önce } & Deney & 37 & 2,81 & 1,60 & 0,26 & $-2,825$ & 0,304 \\
\cline { 2 - 8 } & Kontrol & 36 & 4,06 & 2,14 & 0,36 & & \\
\hline \multirow{2}{*}{ MPÇBT Sonra } & Deney & 37 & 5,46 & 2,01 & 0,33 & 2,984 & $0,004^{* *}$ \\
\cline { 2 - 8 } & Kontrol & 36 & 4,03 & 2,09 & 0,35 & & \\
\hline$* *$ * & & & & & &
\end{tabular}

$* * p<0,01$

Tablo 7 incelendiğinde uygulama öncesi, gruplar arasında MPÇBT toplam puanlarında istatistiksel olarak anlamlı farklılık yoktur $(p=0,304)$. Gruplar arasında MPÇBT toplam puanlarında uygulama sonrası istatistiksel olarak fark anlamlı bulunmuştur $(p<0,01)$. Deney ve kontrol gruplarının arasında MPÇBT'den aldıkları puanlarla ilgili olarak uygulama öncesi anlamlı farklılık olmaması grupların birbirlerine denk olduğunu göstermesi açısından önemlidir. MPÇBT'den alınan puanlar değerlendirildiğinde deney ve kontrol gruplarının aldıkları puanlar arasında uygulama sonrası anlamlı farklılık deney grubu lehine bulunmuştur. Uygulama sonrası deney grubu lehine anlamlı farklılık oluşması, on hafta boyunca öğrencilere uygulanan okuma stratejisi eğitiminin matematik dersi problem çözme becerilerinde olumlu yönde bir farklılık sağladığını ortaya koyması bakımından önemlidir. Okuma stratejisi eğitimi verilen öğrencilerin problem çözmenin ilk basamağı olan "problemi anlama" işlemi gerçekleştirdikleri ve problemleri doğru çözebildiklerini söylemek mümkündür.

\section{Tartışma ve Sonuç}

Yapılan bu araştırma sonucunda, okuma stratejisi eğitimi verilen ortaokul öğrencilerinin matematik dersi problem çözme becerilerinde olumlu yönde bir gelişim olduğu tespit edilmiştir. Okuma stratejisi eğitimi verilen öğrencilerin uygulama sonunda matematik dersi problem çözme başarılarının, okuma stratejisi eğitimi verilmeyen öğrencilere oranla daha yüksek olduğu sonucuna ulaşılmıştır. Bu sonuç okuma becerisinin problem çözme becerisini etkilediğini göstermektedir. Benzer sonuçlara ulan bir araştırmada Usta ve YıImaz (2020) KWL okuma stratejisi eğitimi verdikleri ilkokul 4. sınıf öğrencilerinin, KWL okuma stratejisinin matematik problem çözme becerilerindeki etkisini incelemişlerdir. Deney- kontrol gruplu yarı deneysel desenin kullanıldığı çalışmada, KWL okuma stratejisi eğitimi verilen öğrencilerin, uygulamadan önceki matematik problem çözme başarısı puanlarıyla uygulamadan sonraki puanları arasında uygulamanın sonrası lehine anlamlı farklılık olduğu saptanmıştır. Uygulama sonrası KWL stratejisi eğitiminin verildiği deney grubu öğrencilerinin matematik problem çözme başarılarının bu eğitimin verilmediği kontrol grubu öğrencilerinden daha yüksek olduğu sonucuna ulaşılmıştır. Ulu'nun (2011), rutin olmayan problemlerde öğrencilerin yaptıkları hataların kaynağını belirlemek ve bu hataların giderilmesine yönelik bir uygulamanın yapıldığı çalışma sonucunda ise öğrencilerin rutin olmayan problemlerde en çok okuduğunu anlayamamaktan kaynaklı hatalar yaptıkları belirlenmiştir. Ayrıca strateji eğitimi verilen deney grubu öğrencileri ile strateji eğitimi verilmeyen kontrol grubu öğrencileri arasında rutin olmayan problem çözme başarısı açısından deney grubu lehine anlamlı farklıığın olduğu bulgularına ulaşıımıştır. Usta ve Yılmaz (2020) ve Ulu'nun (2011) yapmış oldukları bu çalışmalar okuma stratejisi ile problem çözme başarısı arasındaki ilişkiyi incelemeleri bakımından yapılan çalışmayla benzerlik göstermektedir. Söz konusu iki çalışma sonuçlarının yürütülen çalışmanın sonucuyla paralellik göstermesi okuma stratejileri ile problem çözme başarısı arasındaki ilişkinin önemini ortaya koyması bakımından dikkat çekicidir.

Problem çözme başarısı ile okuduğunu anlama becerisi arasındaki ilişkiyi ele alan çalışmalar da bulunmaktadır. Memnun ve Kanbur (2020) yapmış oldukları çalışmada, okuduğunu anlama düzeyi düşük olan öğrencilerin problem çözme başarılarının da düşük; okuduğunu anlama düzeyi orta düzeyde olan öğrencilerin problem çözmenin birinci basamağı olan okuduğunu anlama basamağını anladığı ama verilenleri yeterince ayırt edemediği; okuduğunu anlama düzeyleri yüksek olan öğrencilerin problem çözme aşamalarında daha az hata yaptıkları sonuçlarına ulaşılış̧ır. Boz ve Ulusoy'un (2020) ilköğretim 4. sınıf öğrencileriyle yapmış oldukları okuduğunu anlamaya yönelik tutum ile okuduğunu anlama düzeyi ve rutin olmayan problemleri çözme başarısı arasındaki ilişkiyi belirlemeyi amaçladıkları 
çalışmada, anlama düzeyiyle problemleri çözme başarısı arasındaki farkın okuduğunu anlama lehine olduğu bulunmuştur. Araştırmada okuduğunu anlamada yüksek düzeye sahip olan öğrencilerin rutin olmayan problemleri çözme başarılarının da yüksek olduğu sonucuna ulaşılmıştır. Yapılan bu çalışmaların sonuçları, okuma becerisinin yalnızca Türkçe dersiyle ve sözel derslerle ilişkili olmadığını bütün derslerde hatta yaşam boyu önemli ve etkili olduğu düşüncelerini destekler niteliktedir (Aslan, 2017; O'Reilly ve McNamara, 2007; Özaslan, 2006; Sever, 2011; Vilenius-Tuohimaa, Aunola ve Nurmi, 2008; Walker, Zhang ve Surber, 2008). Özcan Tepe'nin (2016) ve Tüzer'in (2016) çalışmalarında betimsel tarama modeli kullanılmış ve iki çalışmada da okuma anlama becerisi ile sayısal dersler arasında okuduğunu anlama becerisinin lehine anlamlı ilişki olduğu sonucuna ulaşılmıştır. Söz konusu çalışmalarla benzer diğer çalışmalar da Çavuşoğlu (2010) ve Göktaş (2010) tarafından yapılmıştır. Çavuşoğlu (2010) beşinci sınıflarla yaptığı çalışmada okuduğunu anlama başarısı ile problem çözme başarısı arasından orta düzeyde ilişki olduğu ve bu ilişkinin de problemi anlama ve plan yapma basamaklarında yüksek olduğu sonucuna varmıştır. Göktaş (2010) ise öğrencilerin okuduğunu anlama becerileriyle matematik dersi başarıları arasında yakın ilişki olduğu bulgularına ulaşmıştır. Hite'nin (2009) ilköğretim beşinci sınıf öğrencilerine okuduğunu anlama eğitimi verilmesiyle problem çözme becerilerinin geliştirilmesini amaçlayan eylem araştırması yönteminin kullanıldığı çalışmasında; öğrencilerle akıcı okuma ve okuduğunu anlama, matematik sözlüğü, problem kurma gibi uygulamalar yapılmıştır. Uygulama öncesi okuduğunu anlama güçlüğü çeken öğrencilerin uygulamaların sonucunda, problem çözme becerilerinde iyileşme olduğu görülmüştür. Tuohimaa, Aunola ve Nurmi (2008) matematiksel sözcük problemleri ile okuduğunu anlama arasındaki ilişkiyi araştırdıkları çalışmada, okuduğunu anlamadaki beceri ile matematiksel sözcük problemlerini çözmedeki beceri arasında yüksek derece ilişki olduğu ve her ikisinin de genel akıl yürütme yetenekleri gerektirdiği bulgularına ulaşılmıştır. Grimm (2008), öğrencilerin okuma stillerinin matematik başarılarına etkisini ölçmek amacıyla gerçekleştirdiği çalışmasında, okuduğunu anlama becerisinin en çok problem çözme ve problemi yorumlamayı etkilediği; matematiksel kavram, tahmin ve işlem becerilerine de az düzeyde de olsa etki ettiği sonucuna ulaşılmıştır. Walker, Zhang ve Surber (2008) yapmış oldukları çalışmada, öğrencilerin okuma becerilerinin düşük olmasından kaynaklı bazı matematik becerilerinin de düşük olma olasılı̆ının olduğu sonucuna ulaşmışlardır. Anderson'un (2010) matematik güçlüğü, anlama güçlüğü yaşayan ve normal gelişim kaydeden öğrencileri problem çözme becerileri açısından 4. sınıfın başından 5. sınıfın sonuna kadar gözlemlediği uzun süreli çalışmanın sonucunda, normal gelişim kaydeden öğrencilerle anlama güçlüğü ve matematik güçlüğü çeken öğrenciler arasındaki farkın giderek arttığı belirlenmiştir. Anderson bu sonuca, sınıf seviyesinin yükselmesiyle problemlerin de zorlaşmasını ve okuduğunu anlamaya olan gereksinimin artmasını gerekçe olarak göstermiştir. Mevcut araştırma sonuçları ile alanyazında okuma stratejileri ve problem çözme başarısı, okuduğunu anlama ve problem çözme başarısını konu alan araştırma sonuçlarının birbiriyle paralellik göstermektedir (Anderson, 2010; Boz ve Ulusoy, 2020; Çavuşoğlu, 2010; Hite, 2009; Grimm, 2008; Göktaş, 2010; Memnun ve Kanbur, 2020; Özcan Tepe, 2016; Tatar ve Soylu, 2006; Tuohimaa, Aunola ve Nurmi, 2008; Tüzer,2016; Ulu, 2011; Usta ve Yılmaz, 2020; Walker, Zhang ve Surber, 2008). Yapılan çalışmalarda okuduğunu anlama becerisi ile problem çözme başarısı arasındaki ilişki düzeyleri kimi çalışmalarda yüksekken kimi çalışmalarda bu ilişki düzeyi daha düşüktür. Çalışmaların ilişki düzeyi noktasında bulguları arasında farklııkların oluşmasının; çalışma grupları, sınıf seviyeleri, yapılan uygulamalar, araştırmaların amaçları vb. değişkenlerden kaynaklı olduğu söylenebilir.

\section{Öneriler}

Okuma stratejisi eğitiminin matematik dersi problem çözme becerisi üzerindeki etkisi dikkate alındığında; araştırmacılar, öğretmenler, Türkçe Dersi Öğretim Programı, Türkçe ders kitapları gibi konuların göz önünde bulundurulması gerekmektedir. Bu konulardan hareketle şu önerilerde bulunulabilir:

1. Ortaokul 6. sınıf öğrencileriyle sınırlanan, okuma stratejisi eğitimi verilerek okuduğunu anlamanın geliştirilmesine yönelik olan bu çalışma, farklı sınıf seviyelerinde de yapılabilir. 
2. Bu araştırma bir eğitim öğretim yılı ile sınırlandırımıştır. Konuyla ilgili daha uzun bir süreç planlanıp kapsamlı ve ayrıntılı çalışmaların yapılmasının alana katkı sağlayacağı düşünülmektedir.

3. Okuduğunu anlama stratejileri konusuna programlarda daha ayrıntılı biçimde yer verilmeli ve stratejiler konusunda öğretmenlerin de yeterli derecede bilgi sahibi olmaları sağlanmalıdır.

4. Öğretmenler, yalnızca ders kitabını kullanmamalı farklı okuma stratejilerini kullanabilecekleri nitelikli metinlerle öğrencileri buluşturmalıdır.

5. Ders kitaplarında yer alan metinlerin geniş bir araştırma, uygulama ve değerlendirme sonucu belirlenmesine özen gösterilmelidir.

\section{Araştırma ve Yayın Etiği}

Bu çalışmada "Yükseköğretim Kurumları Bilimsel Araştırma ve Yayın Etiği Yönergesi" kapsamında uyulması belirtilen tüm kurallara uyulmuştur. Yönergenin ikinci bölümü olan "Bilimsel Araştırma ve Yayın Etiğine Aykırı Eylemler" başlığı altında belirtilen eylemlerden hiçbiri gerçekleştirilmemiştir.

\section{Etik Kurul izni}

Araştırma Millî Eğitim Bakanlığına bağlı bir ortaokulda gerçekleştirildiği için Millî Eğitim Bakanlığından gerekli izinler alınmıştır. Ankara Üniversitesi Sosyal Bilimler Alt Etik Kurulu, Millî Eğitim Bakanlığından alınan izinlerin yeterli olması ve insan üzerinde yapılan bir çalışma olmaması gerekçesiyle etik kurul onayına ihtiyaç duyulmadığı kararı almıştır.

Kurul adı $=$ Ankara Üniversitesi Sosyal Bilimler Alt Etik Kurulu

Karar tarihi $=22 / 04 / 2019$

Belge sayı numarası $=182$

\section{Yazarların Katkı Oranı}

Bu araştırmada 1. Yazarın katkı oranı \%60, 2. Yazarın katkı oranı \%20, 3. yazarın katkı oranı $\% 20$ 'dir

\section{Çıkar Çatışması}

Bu araştırmada, çıkar çatışması teşkil edebilecek bir durum yoktur.

\section{Kaynaklar}

Ajello A. M., Caponeram E. and Palmerio L. (2018). Italian students' results in the PISA mathematics test: does reading competence matter?. European Journal Psychology of Education, 33(3), 505-520.

Akyol, H. (2012). Programa uygun Türkçe öğretim yöntemleri. Ankara: Pegem Akademi.

Anderson, U. (2010). Skill development in different components of arithmetic and basic cognitive functions: findings from a 3-year longitudinal study of children with different types of learning difficulties. Journal of Educational Psychology, 102(1), 115-134

Aslan, C. (2017). Örnek eğitim durumlarıyla Türkçe - Türk dili ve edebiyatı öğretimi. Ankara: Anı Yayıncilık.

Baştuğ, M.; Hiğde, A.; Çam, E.; Örs, E. ve Efe, P. (2019). Okuduğunu anlama becerilerini geliştirme stratejiler, teknikler, uygulamalar. Ankara: Pegem Akademi.

Bloom. (1998). Insan nitelikleri ve okulda öğrenme (D. A. Özçelik, Haz.). İstanbul: Millî Eğitim Basımevi. Bloomfield, L. (1942). Linguistics and reading. The Elementary English Review, 19(4), 125- 130.

Boz, i. ve Ulusoy M. (2020). Illkokul 4. sınıf öğrencilerinin okuma tutumu ile okuduğunu anlama düzeyi ve rutin olmayan problem çözme başarısı arasındaki ilişkinin incelenmesi. Anadolu Kültürel Araştırmalar Dergisi, 4(1), 13-24.

Büyüköztürk, Ş. (2014). Deneysel desenler. Ankara: Pegem Akademi.

Büyüköztürk, Ş. (2000). Bilimsel araştırma yöntemleri. Ankara: Pegem Akademi. 
Çavuşoğlu, E. (2010). Illköğretim beşinci sını öğrencilerinin okuduğunu anlama düzeyi ile matematik problemlerini çözme başarısı arasındaki ilişkinin incelenmesi (Yayımlanmamış Yüksek Lisans Tezi). Gazi Üniversitesi, Ankara.

Cronbach, L. J. (2004). My current thoughts on coefficient alpha and successor procedures. Educational and Psychological Measurement, 64, 391-418.

Cronbach, L. J. (1951). Coefficient alpha and the internal structure of tests. Psychometrika, 16, 297334.

Goos, M.; Galbraith, P. and Renshaw, P. (2000). A money problem: a source of insight into problem solving action. International Journal for Mathematics Teaching and Learning, 80, 1-21.

Göktaş, Ö. (2010). Okuduğunu anlama becerisinin ilköğretim ikinci kademe matematik dersindeki akademik başarıya etkisi (Yayımlanmamış Yüksek Lisans Tezi). İnönü Üniversitesi, Malatya.

Grimm, K. J. (2008). Longitudinal associations between reading and mathematics. Developmental Neuropsychology, 33, 410-426.

Güneş, F. (2013). Türkçe öğretimi yaklaşımlar ve modeller. Ankara: Pegem Akademi.

Gürses, T. (2002). Reading strategiese employed by ELT learners at advanced level (Yayımlanmamış Yüksek Lisans Tezi). Atatürk Üniversitesi, Erzurum.

Hite, S. (2009). Improving problem solving by improving reading skills. Math in the Middle Institute Partnership Summative Projects for MA Degree. University of Nebraska - Lincoln.

ilhan, C. (2014). SQ3R akıcı okuma stratejisinin ilkokul 4. sınıf öğrencilerinin fen ve teknoloji dersi akademik başarıları, problem çözme becerileri ve fen tutumlarına etkisi (Yayımlanmamış Yüksek Lisans Tezi). Ahi Evran Üniversitesi, Sosyal Bilimler Enstitüsü, Kırşehir.

İzmirli, E. ve İzmirli, S. (2016). 6. sınıf matematik konu kitabı. Sakarya: Palme Yay.

Jordan, N. C.; Hanich, L. B. and Kaplan, D. (2003). A longitudinal study of mathematical competencies in children with specific mathematics difficulties versus children with comorbid mathematics and reading difficulties. Child Development, 74, 834-850.

Karekök Yayınları. (2016). 6. sınıf matematik soru bankası. İstanbul: Karakök Yay.

Karatay, H. (2014). Okuma eğitimi kuram ve uygulama. Ankara: Pegem Akademi.

Karasar, N. (2005). Bilimsel araştırma yöntemi. Ankara: Nobel Yayın Dağıtım.

Kıvrak, Y. (2014). Okuma-anlamadaki başarının matematik başarısına etkisi (Yayımlanmamış Yüksek Lisans Tezi) Uludağ Üniversitesi Eğitim Bilimleri Enstitüsü, Bursa.

Memnun, D. S. ve Kanbur, N. İ. (2020). Üçüncü sınıf öğrencilerinin okuma becerilerine göre problem çözme başarıları ve çözüm sürecinde karşılaştıkları güçlükler. Uluslararası Toplum Araştırmaları Dergisi, 15(22), 927-965.

Olkun, S. ve Toluk, Z. (2002). ilköğretimde etkinlik temelli matematik öğretimi. Ankara: Anı Yayıncılık.

O'Reilly, T. and McNamara, D. S. (2007). The impact of science knowledge, reading skill and reading strategy knowledge on more traditional "High-Stakes" measures of high school students' science achievement. American Educational Research Journal, 44(1), 161-196.

Özcan Tepe, Y. (2016). Ortaokul öğrencilerinin okuduğunu anlama becerisi ile matematik dersinde problem çözme başarısı arasındaki ilişki (Yayımlanmamış Yüksek Lisans Tezi). Fırat Üniversitesi, Eğitim Bilimleri Enstitüsü, Elazığ.

Özaslan, A. (2006). Kelime oyunları ile kelime dağarcı̆̆ının geliştirilmesinin okuduğunu anlama düzeyine etkisi, (Yayımlanmamış Yüksek Lisans Tezi). Selçuk Üniversitesi Sosyal Bilimler Enstitüsü, Konya.

Özdemir, S. (2013). Ortaöğretim öğrencilerinin okuma alışkanlık ve tutumlarıyla fen, matematik derslerindeki akademik başarıları arasındaki ilişkinin incelenmesi (İzmir-Buca ilçesi örneği) (Yayımlanmamış Doktora Tezi). Dokuz Eylül Üniversitesi Eğitim Bilimleri Enstitüsü, İzmir.

Özsoy, G.; Kuruyer, H.G. ve Çakıroğlu, A. (2015). Evaluation of students' mathematical problem solving skills in relation to their reading levels. International Electronic Journal of Elementary Education, 8(1), 113-132.

Sever, S. (2011). Türkçe öğretimi ve tam öğrenme. Ankara: Anı Yayıncılık.

Tuohimaa, P.M.V., Aunola, K. and Nurmi J.E. (2008). The association between mathematical word problems and reading comprehension. Educational Psychology, 28(4), 409-426. 
Tüzer, A. (2016). Ortaokul sekizinci sınıf öğrencilerinin okuma alışkanlıkları ile sayısal ders başarıları arasındaki ilişkinin incelenmesi (Yayımlanmamış Yüksek Lisans Tezi). Kahramanmaraş Sütçü İmam Üniversitesi Sosyal Bilimler Enstitüsü, Kahramanmaraş.

Ulu, M. (2011). Ilköğretim beşinci sını öğrencilerinin rutin olmayan problemlerde yaptıkları hataların belirlenmesi ve giderilmesine yönelik bir uygulama (Yayımlanmamış Doktora Tezi). Gazi Üniversitesi Eğitim Bilimleri Enstitüsü, Ankara.

Usta, N. ve Yılmaz M. (2020). Impact of the KWL reading strategy on mathematical problem-solving achievement of primary school 4 th graders. The Journal of Educational Research, DOI: 10.1080/00220671.2020.1830017.

Tatar, E. ve Soylu, Y. (2006). Okuma-anlamadaki başarının matematik başarısına etkisinin belirlenmesi üzerine bir çalışma. Kastamonu Eğitim Dergisi, 14(2), 503-508.

TDK. (2020). Türkçe sözlük. Ankara: TDK Yayınları.

Tudem. (2015). Tüm dersler soru bankası. İzmir: Tudem Yay.

Tüzer, A. (2016). Ortaokul sekizinci sınıf öğrencilerinin okuma alışkanlıkları ile sayısal ders başarıları arasındaki ilişkinin incelenmesi (Yayımlanmamış Yüksek Lisans Tezi). Kahramanmaraş Sütçü İmam Üniversitesi Sosyal Bilimler Enstitüsü, Kahramanmaraş.

Vilenius Tuohimaa, P. M.; Aunola, K. and Nurmi, J. E. (2008). The association between mathematical word problems and reading comprehension. Educational Psychology, 28 (4), 409-426.

Walker, C. M.; Zhang, B. and Surber, J. (2008). Using a multidimensional differential item functioning framework to determine if reading ability affects student performance in mathematics. Applied Measurement in Education, 21(2), 162-181.

Yalçın, A. (2018). Son bilimsel gelişmeler ışığında Türkçenin öğretimi yöntemleri. Ankara: Akçağ Yayınları.

Yılmaz Ay, E. ve Atış, S. (2105). 6. sınıf matematik soru bankası. Ankara: Esen Yayınları.

Yurttaş Kumlu, G. D. (2016). Doğrudan ve akranla öğretimin fen bilgisi öğretmen adaylarının ısı-sıcaklık konusundaki kavramsal anlamalarına etkisinin okuma stratejileri bakımından incelenmesi (Yayımlanmamış Doktora Tezi). Gazi Üniversitesi Eğitim Bilimleri Enstitüsü, Ankara.

\section{Introduction}

\section{Extended Abstract}

Native language teaching is carried out by developing four basic language skills. An individual's ability to use his/her native language effectively is related to the development of these linguistic skills. Each skill is individually very important and complementary, and different practices should be conducted to develop each area. As one of these skills, reading is a complex process including physical and mental processes and it is realized only through comprehension. If comprehension does not occur, it remains only in its physical dimension and does not take place completely. Therefore, the notion of "comprehension" is highly important and it highlights the mental dimension of reading.

Reading skills acquired and developed during school period are important both in native language teaching and in the lives of students. Various studies should be conducted to develop reading comprehension skills, and strategies supporting reading comprehension should be taught to students. The concept of strategy in language teaching can be expressed as planned approaches to a work. Accordingly, reading comprehension strategies provide guidance to individuals to consciously realize comprehension during reading or to find solutions when comprehension is not achieved. Although they are categorized based on the process as before, while and after reading, the number of strategies used at every stage is quite high. Some of these strategies are SQ3R, K-W-L, Multiple pass strategy, SCAN and RUN, and note-taking. Although each strategy has a specific aim, common aims of these strategies are to enable students to perceive texts from different perspectives and to develop highlevel thinking skills such as critical and creative thinking.

An education-training process enabling individuals to adapt to new situations and develop problem solving skills is very important. Problem solving can be defined as generating solutions or ways for questions and issues. It is a complex process requiring mental process and multi-faceted thinking. It consists of understanding the problem, choosing the information required for solution, converting 
the selected information into mathematical images and reaching the solution by performing necessary operations. The first stage of problem solving in mathematics is to understand the problem by reading. Only after the problem is read and understood, it is possible to take the necessary actions. Generally, students having problems in reading comprehension cannot solve problems. For students to reach the result, Turkish and mathematics lessons complement each other in terms of understanding and using the necessary concepts.

Accordingly, it is necessary to plan the native language teaching process well and to train students to ensure that these skills are used effectively. Therefore, it is thought that reading strategy education will improve students' problem solving skills in mathematics. For this reason, in this study, the effect of reading strategies on middle school grade students' problem solving skills in mathematics is highlighted; and the answer of the question that "Is there a significant difference between mathematical problem solving skills of the grade students who are provided reading strategies education and mathematical problem solving skills of the students who are not provided this education?" was searched.

\section{Method}

In this study, a quasi-experimental design with pretest-posttest control group including activities planned to determine the effect of reading strategies education on students' mathematical problem-solving skills, was used. Mathematical problem solving skills of the experimental and control group students were measured before (pre-test) and after the application (post-test), and thus, whether the activities prepared for reading comprehension had an effect in the experimental group was determined.

To collect data, "Mathematical Problem Solving Achievement Test" (MPSAT) was used. MPSAT was developed by the researcher to measure the mathematical problem solving success of the experimental and control groups by taking mathematics education expert opinions.

Same texts were simultaneously studied by the same teacher for ten weeks in the experimental and control groups. However, while texts were studied only with the activities in the textbook and workbook in the control group, the teaching process was carried out with the activities and practices planned by the researcher according to the reading strategies education in the experimental group.

\section{Result and Discussion}

As a result of the study, it was determined that there was a positive development in the problem solving skills of middle school students provided reading strategy education. At the end of the application, it was concluded that students provided reading strategy education had higher mathematical problem solving success than students who did not receive this education. Usta and Yılmaz (2020) analyzed same effects on mathematical problem solving skills of $4^{\text {th }}$ graders to whom they provided KWL reading strategy education. In the study where a quasi-experimental design with pretest-posttest control group was used it was determined that there was a significant difference between the mathematical problem solving success scores of students before and after the application in favor of the students who were provided the KWL reading strategy education. As a result of another study in which an application was carried out to determine and eliminate the source of errors made by students in non-routine problems, it was determined that students mostly made mistakes in nonroutine problems due to not being able to understand what they read, and that there was a significant difference between the experimental group who received reading comprehension strategies and the control group in favor of the experimental group, in terms of success in non-routine problem solving (Ulu, 2011). These studies carried out by Usta and YIImaz (2020) and Ulu (2011) show similarities with the study in terms of analyzing the relationship between reading strategy and problem solving success. The fact that their results are in parallel with the results of this study is remarkable and it reveals the importance of the relationship between reading strategies and problem solving success.

Results of the current research are in parallel with the results of the researches in the literature on reading strategies and problem solving success, reading comprehension, and problem solving 
success (Anderson, 2010; Boz and Ulusoy, 2020; Çavuşoğlu, 2010; Hite, 2009; Grimm, 2008; Göktaş, 2010; Jordan et al., 2003; Memnun and Kanbur, 2020; Özcan Tepe, 2016; Tatar and Soylu, 2006; Tuohimaa, Aunola and Nurmi, 2008; Tüzer, 2016; Ulu, 2011; Usta and Yılmaz, 2020; Walker, Zhang and Surber, 2008). In the conducted studies, while the level of relationship between reading comprehension skill and problem solving success is higher in some studies, it is lower in other studies. It can be stated that the differences between the findings of the studies in terms of the relationship level are due to variables such as study groups, class levels, practices, and aims of the research. 